\title{
A Experimentoteca do Centro de Divulgação Científica e Cultural (CDCC-USP) e o Ensino por Investigação: Compromissos Teóricos e Esforços Práticos
}

\section{Experimentoteca of the Centre for Scientific and Cultural Dissemination (CDCC-USP) and Inquiry-Based Learning: Theoretical Commitments and Practical Efforts}

\section{Rafael Cava Mori ${ }^{-10}$ Brasil Antonio Aprigio da Silva Curvelo ${ }^{(1)}$ Brasil}

A Experimentoteca é um projeto desenvolvido pelo Centro de Divulgação Científica e Cultural (CDCC-USP), e busca prover as escolas da educação básica com materiais para o ensino experimental. Este estudo procura investigar quais são os compromissos teóricos da Experimentoteca com o ensino por investigação e como estes são acompanhados de esforços práticos, por parte de seus idealizadores e seus usuários, visando a realização desse tipo de atividades experimentais. Os compromissos teóricos foram inferidos a partir da análise de coocorrências de substantivos na obra O livro da Experimentoteca, tomada como cânone do projeto quanto à sua fundamentação pedagógica. A identificação dos esforços práticos decorreu da análise categorial de roteiros que acompanham os kits da Experimentoteca, seguida de um estudo documental dos trabalhos que já a tomaram como objeto. Os resultados indicam a existência de contradições entre os fundamentos teóricos do projeto (que manifestam uma preferência pela abordagem investigativa no ensino) e suas formas de apresentação e de uso na prática (que esbarram em limites como a estrutura organizacional da educação básica). O texto finaliza com apontamentos para a superação desse cenário contraditório.

Palavras-chave: museus e centros de ciências; Experimentoteca; relação teoria-prática.

The Experimentoteca ("Experiment Library") is a project developed by the Centre for Scientific and Cultural Dissemination (CDCC-USP), and its goal is to provide basic education schools with teaching material for experiment-based teaching. This study aims to investigate the Experiment Library's commitments to inquiry-based learning, and how these are accompanied by practical efforts on the part of its creators and users to conduct this type of experiment-based activities. The theoretical commitments were inferred from a co-occurrence analysis (focused on substantives) of O livro da Experimentoteca ("The Experiment Library book"), which the project has taken as the canon of its pedagogical foundation. As for the practical efforts, we identified them 
by an categorial analysis of the scripts that accompany the Experiment Library's kits, and then conducting a documentary study on existing research particularly about this project. Results indicate that there are contradictions between the project's theoretical foundations (which manifest a preference for inquiry-based learning) and its forms of presentation and use on practices (which face limitations such as the organizational structure of basic education). We close the text with notes meant for overcoming this contradictory scenario.

Keywords: science museums and centers; Experimentoteca; theory-practice relationship.

\section{Introdução}

O ensino por investigação, particularmente em suas vertentes relacionadas com o trabalho experimental na educação científica, representa uma tentativa de superar a influência do empirismo-indutivismo ou do indutivismo ingênuo nas práticas pedagógicas. No caso da experimentação didática, tais concepções redundam, frequentemente, em visões imprecisas e estereotipadas sobre o fazer e $\mathrm{o}$ aprender ciências, em que o experimento passa a ser visto ou como fonte de dados neutros da realidade, ou como instância verificadora de teorias. Por sua vez, as práticas experimentais influenciadas pela abordagem investigativa, ao considerar aspectos da própria natureza das ciências - permitindo que os alunos conheçam a heurística da modelagem, o caráter argumentativo da atividade científica e os condicionantes sociais das ciências -, se apresentam como fonte de problematização ou como teste de hipóteses (Kasseboehmer, Hartwig, \& Ferreira, 2015). Nesse sentido, colaboram para o exercício, por parte dos estudantes, de habilidades mais cognitivamente desafiadoras, em comparação com os experimentos mais estruturados ou com maior grau de direcionamento (Araújo, \& Abib, 2003).

Se, portanto, o ensino por investigação se orienta por uma visão mais crítica sobre a práxis científica, cabe perguntar se e como as iniciativas concretas em prol do trabalho experimental investigativo, atualmente em curso nas instituições educacionais, vêm se desenvolvendo de modo a também observar a necessária imbricação entre teoria e prática - nesse caso, no âmbito especificamente pedagógico.

A presente pesquisa, orientada por um enfoque crítico-dialético - que, segundo Gamboa (2004), se fundamenta "na lógica interna do processo e nos métodos que explicitam a dinâmica e as contradições internas dos fenômenos e explicam as relações entre homem-natureza, entre reflexão-ação e entre teoria-prática" (p. 98) -, toma como objeto a Experimentoteca, ação desenvolvida já há mais de três décadas pelo Centro de Divulgação Científica e Cultural da Universidade de São Paulo (CDCC-USP).

As questões de pesquisa estão elaboradas nos seguintes termos:

Quais são os compromissos teóricos da Experimentoteca com o ensino por investigação?

Como esses compromissos são acompanhados de esforços práticos, por parte 
de idealizadores e de usuários da Experimentoteca, visando a realização de atividades experimentais mais coerentes com a abordagem investigativa?

Para respondê-las, foram analisados diversos dados. O estudo dos compromissos teóricos foi desenvolvido analisando-se O livro da Experimentoteca, tomado como o principal cânone do projeto do CDCC quanto a sua fundamentação pedagógica e epistemológica. Por sua vez, a investigação dos esforços práticos recorreu à análise de roteiros que acompanham os materiais da Experimentoteca e ao estado do conhecimento sobre o projeto, reanalisando dados já coligidos por outros autores. Destinamos duas seções do texto a esses dois conjuntos de estudos, seguindo-se nossas considerações finais.

Antes, dedicamos a próxima seção para contextualizar a criação da Experimentoteca no quadro da emergência da função educativa dos museus e centros de ciências.

\section{A Experimentoteca: do não escolar para o escolar}

$\mathrm{Na}$ atualidade, estão colocados questionamentos quanto ao emprego dos termos educação formal/não formal/informal, como bem observa Marandino (2017). Tradicionalmente identificados como promotores de uma educação não-formal - ao menos nos países lusófonos -, museus e centros de ciências frequentemente estabelecem parcerias com instituições especificamente educacionais (o que contribuiria para a formalização de sua missão), mas também são frequentados com interesses mais próximos do entretenimento do que da aprendizagem (e desse ponto de vista, são espaços para uma educação mais informal). De modo a evitar tais dificuldades, seguiremos a tipologia proposta pelo trabalho de Mori e Curvelo (2016). Segundo os pesquisadores, pode-se considerar que as instituições museais praticam, em geral, formas de educação não escolar sistematizada.

No mesmo trabalho, Mori e Curvelo traçam um breve histórico dessas instituições e consideram que a função educativa dos museus floresce - e se sistematiza progressivamente - a partir do século XIX, impulsionada pela Revolução Industrial e a consequente necessidade de familiarizar a população com os recentes avanços científicotecnológicos de então (Cazelli, Marandino, \& Studart, 2003; Gaspar, 2006; Marandino, 2008; McManus, 1992). No século XX, com a pós-modernidade, a noção de objeto expositivo aos poucos vai se dessacralizando (Ruiz, 2003, citado em Gaspar, 2006), o que contribui não apenas para a desmaterialização e virtualização das exposições museográficas, mas também para a emergência de uma outra função museal além da guarda, preservação e exibição de artefatos: os museus passam a elaborar e operar as chamadas ações educativas. Estas, direcionadas a um público escolar, mas geralmente capazes de abranger audiências mais amplas, muitas vezes avançam para outros espaços além das dependências físicas dos museus.

O CDCC, criado em 1980 (no campus de São Carlos da USP) não como Centro, mas como Coordenadoria de Divulgação Científica e Cultural, é caracterizado 
justamente por tais ações, cujo destaque faz sombra a suas exposições de ciências. Gaspar (2006) o compara ao Ontario Science Centre, localizado em Toronto, instituição modelar no que tange à combinação de exposições de experimentos interativos com o apoio à educação escolar, mediante convênios e estímulos à frequência regular dos estudantes a suas instalações. De fato, ao lado de 12 atividades elencadas como as de maior destaque do CDCC (excursões e projetos de educação ambiental; orientações, plantões de dúvidas e minicursos para estudantes; orientação técnico-científica e cursos para professores da educação básica; palestras e debates sobre astronomia; cineclube; biblioteca e videoteca; atendimentos a distância), apenas um item trata da realização de exposições permanentes e itinerantes (Ferreira, \& Schiel, 2001).

Dentre tais ações educativas, seguramente a Experimentoteca é aquela de maior destaque. Trata-se de um projeto herdeiro das iniciativas pioneiras do Instituto Brasileiro de Educação, Ciência e Cultura (IBECC). Essa instituição, criada em 1950 e vinculada à USP e à Unesco, orientou os diversos setores preocupados com a educação científica brasileira, incluindo os museus, a repensar suas atividades e produzir materiais instrucionais - antecipando-se às potências do ocidente, que só viriam a criar iniciativas semelhantes quase nos anos 1960 (Krasilchik, 1987). Assim, ainda na década de 1950 o IBECC criou o projeto Iniciação às ciências, produzindo kits de experimentos para a educação básica que continham, além de material experimental, um manual com orientações e um folheto com leituras suplementares. Mais tarde, passou a traduzir e adaptar os projetos curriculares estadunidenses e ingleses, produzidos às portas dos anos 1960. Tais materiais, orientados de início pela pedagogia tecnicista, propugnavam a aprendizagem por redescoberta através de atividades que conduzissem à apreensão do método científico, geralmente baseadas na experimentação. A grande demanda pela produção de materiais, por parte do IBECC, foi uma das razões que levou à criação da Fundação Brasileira para o Desenvolvimento do Ensino de Ciências (Funbec) em 1966. Até o final dessa década, a parceria IBECC-Funbec geraria a produção de outros kits experimentais, como as coleções Mirim (30 kits) e Cientistas de amanhã (21 kits). $\mathrm{Na}$ década seguinte teve destaque o projeto Os cientistas (1972), que compreendeu a elaboração de 50 kits de material experimental vendidos em bancas de jornal. Para Gaspar (2006), tratou-se da "mais importante iniciativa voltada à divulgação científica desenvolvida no Brasil até nossos dias" (p. 43). Seu primeiro volume vendeu perto de 200.000 cópias e as vendagens se estabilizaram, em volumes futuros, em cerca de 50.000 exemplares.

Dessa forma, orientando-se pelos anseios do IBECC e dos projetos curriculares mencionados no parágrafo anterior, a Experimentoteca foi idealizada por Dietrich Schiel (1940-2012) de forma a atender as reivindicações de professores da educação básica de São Carlos e região. Estes, organizados no I Simpósio de Integração Universidade-Escolas de $1^{\circ}$ e $2^{\circ}$ Graus (1979), mostraram-se desejosos de maior colaboração, por parte dos docentes das universidades públicas instaladas no município (além da USP, a Universidade Federal de São Carlos - UFSCar), para o suporte material e o aprimoramento de sua 
atuação pedagógica nas escolas municipais e estaduais. Assim, o projeto foi concebido como um conjunto de kits experimentais itinerantes, que seriam disponibilizados aos usuários mediante um sistema de empréstimos gratuitos, semelhante à forma como livros são emprestados em bibliotecas - daí o nome "Experimentoteca".

A preparação dos primeiros protótipos e roteiros para a experimentação escolar teve início em 1984 (Schiel, 1998, 2001; Schiel, Curvelo, \& Ferreira, 2004). Os quatro anos passados entre a criação do CDCC e o início de sua principal atividade provavelmente decorreram da necessidade de predispor a estrutura física, organizacional e administrativa da então Coordenadoria, para a realização de seus grandes projetos.

Três questões precisaram ser atacadas de modo a viabilizar a Experimentoteca: a questão operacional, a questão do design e a questão propriamente pedagógica. A primeira foi desenrolada através dos anos, facilitada pelo fato de que o CDCC sempre ocupou o mesmo prédio, na região central de São Carlos - favorecendo os deslocamentos dos kits experimentais para as escolas e a própria difusão do projeto. A questão do design foi equacionada por meio de diferentes soluções, que conduziram à criação de caixas de madeira e de plástico especificamente desenhadas para a disposição dos componentes dos kits. Vale mencionar que, desde sua idealização, a Experimentoteca almejou se apresentar como um suporte a atividades que rompessem com a pedagogia tradicional, descartando-se, de início, a criação de kits experimentais meramente demonstrativos. Então, considerando uma realidade educacional em que as salas de aula são ocupadas por até 40 estudantes, a questão do design buscou otimizar a disposição de materiais nessas caixas, permitindo o trabalho simultâneo de 10 grupos de até 4 alunos. Ainda, as soluções para armazenagem dos materiais experimentais em caixas transportáveis por uma única pessoa foram orientadas por preceitos do campo do design industrial, subordinando-se a relação forma/conteúdo a elementos como qualidade estética, possibilidade de produção em série e satisfação dos usuários (Schiel, Curvelo, \& Ferreira, 2004). Finalmente, a questão propriamente pedagógica planificou a elaboração dos kits em ciclos de desenvolvimento-aplicação-investigação-novo desenvolvimento. Esses processos ocorreram em duas etapas: a primeira, nos anos 1980, no desenvolvimento de kits para a disciplina de Ciências Naturais, do então $1^{\circ}$ grau da educação básica; e a segunda, já nos anos 2000, criou kits para as disciplinas de Física, Química e Biologia do atual ensino médio, e de Matemática para toda a educação básica (Meneghtetti, 2011). Schiel, Curvelo e Ferreira (2004) explicam a importância dessa fase de testes:

A participação dos professores exerce um papel importante não somente na utilização do material didático, mas também na concepção desse mesmo material. A metodologia do projeto Experimentoteca prioriza ações de intervenção na escola que estejam baseadas na aprendizagem ativa/participativa por meio de atividades cooperativas/ interdisciplinares, pois os resultados de pesquisa na área de educação têm mostrado que a simples introdução de inovações tecnológicas, sem a fundamentação teórica/ metodológica inerente, é infrutífera e ineficiente. [...] Uma maneira de minimizar esse fator de resistência para a adoção e difusão de propostas inovadoras na educação é envolver os professores na fase de concepção do projeto e, posteriormente, na difusão 
dos mesmos, dando ao material produzido uma feição articulada com o cotidiano escolar (p. 150-151).

A declaração acima, emitida por ex-coordenadores do projeto, expõe uma diferença entre a Experimentoteca e empreendimentos afins, como os projetos estadunidenses e ingleses que definiram reformas curriculares naqueles países em meados do século XX. Gaspar (2014), comentando os resultados decepcionantes desses projetos, aponta como uma de suas causas o alheamento da realidade educacional por parte dos formuladores:

Além de leigos em pedagogia, esses especialistas só conheciam o ensino médio ou o equivalente dele em seus países por experiência própria, baseada em seus tempos de estudante. E, a julgar pelo alto nível por eles atingido nas suas carreiras, pode-se supor que a maioria era constituída de alunos diferenciados, que haviam frequentado escolas igualmente diferentes daquelas a quem dirigiram suas propostas. Daí o irrealismo dos projetos e, sobretudo, dos currículos sugeridos, cujos conteúdos, muito distintos daqueles adotados até então nas escolas de todo o mundo, não eram dominados pelos professores, pois estes não tinham sido preparados para essa nova e exigente tarefa (p. 30).

Entretanto, tal peculiaridade da Experimentoteca nem sempre é reconhecida ou ressaltada pelos estudiosos. Na literatura brasileira sobre o ensino de ciências, um dos mais destacados comentários à Experimentoteca, elaborado por intermédio da leitura de duas dissertações de mestrado que a tomaram como objeto, pôs em relevo sua filiação aos projetos de ensino estadunidenses (Megid Neto, 1999):

Propostas metodológicas como as contidas no Projeto Experimentoteca tentam reeditar as principais características destes projetos de ensino de trinta anos atrás, desconsiderando especialmente o avanço do pensamento educacional e das pesquisas na área, nos anos 80 . Avanços que incorporam o movimento construtivista no ensino escolar, as abordagens histórico-críticas, o resgate aos conhecimentos e experiências prévias dos educandos, as relações entre ciência, tecnologia e sociedade, a busca pela formação de um cidadão crítico, participativo, potencial agente de transformação social. Avanços que não são assimilados no Projeto Experimentoteca (p. 174).

Visando responder a tais críticas e distanciar a Experimentoteca do tecnicismo dos anos 1970 e das abordagens empiristas-indutivistas típicas daquele momento histórico, o CDCC elaborou, a partir de 1998, O livro da Experimentoteca. A obra, publicada no ano 2000, propõe fundamentos teóricos para as atividades experimentais escolares, buscando aproximar a Experimentoteca de tendências do ensino de ciências de então.

Atualmente a Experimentoteca se encontra disseminada para mais de 30 universidades, museus e centros de ciências nas cinco regiões do Brasil. A Figura 1 elenca cronologicamente os principais marcos do projeto até os dias de hoje, destacando também as fontes de dados das próximas seções - O livro da Experimentoteca e os trabalhos em nível de pós-graduação que a tomaram como objeto (Canales, 2006; Diniz, 1992; Joaquim, 1992; Mori, 2014). Na Figura 2, por sua vez, constam fotografias de alguns dos kits experimentais disponíveis. 


\begin{tabular}{|c|c|}
\hline Ano & contecimento \\
\hline 1979 & $\begin{array}{l}\text { Simpósio de Integração Universidade-Escolas de } 1^{\circ} \text { e } 2^{\circ} \text { graus: professores da educação } \\
\text { básica de São Carlos reivindicam maior apoio por parte das universidades, especialmente } \\
\text { no tocante ao fornecimento de materiais instrucionais. }\end{array}$ \\
\hline 1980 & $\begin{array}{l}\text { Resolução n. 1.988/1980, do Instituto de Física e Química de São Carlos (IFQSC-USP), } \\
\text { cria a CDCC. Início das atividades em uma das salas no prédio da R. Nove de Julho, } 1227 .\end{array}$ \\
\hline 1983 & A CDCC ocupa integralmente o prédio da R. Nove de Julho, à época, cedido para a USP. \\
\hline 1984 & $\begin{array}{l}\text { Programa de Aperfeiçoamento do Desenvolvimento Científico e Tecnológico (PADCT), } \\
\text { do Banco Mundial, possibilita ampliar as atividades da CDCC. Início da Experimentoteca. } \\
\text { Lei Municipal n. 9.187/1984 declara a CDCC Instituição de Utilidade Pública. }\end{array}$ \\
\hline 1985 & $\begin{array}{l}\text { Compra do prédio da R. } 9 \text { de Julho pela USP. Contratação de Vanilde de Fátima Bongiorno } \\
\text { como educadora responsável pela Experimentoteca (posto em que permanece até hoje). } \\
\text { Disponibilização do primeiro conjunto de kits, para } 5^{\mathrm{a}} \text { série do } 1^{\circ} \text { grau. }\end{array}$ \\
\hline 1988 & $\begin{array}{l}\text { Encerramento da fase de teste e desenvolvimento da Experimentoteca, com aprovação dos } \\
\text { protótipos por professores da educação básica. }\end{array}$ \\
\hline 1989 & $\begin{array}{l}\text { Disponibilização de kits para o ensino de Ciências Naturais, com os temas Ar, Água e Solo, } \\
\text { Seres Vivos, Corpo Humano e Física e Química. }\end{array}$ \\
\hline 1990 & Projeto de disseminação da Experimentoteca para outras localidades do país. \\
\hline 1991 & $\begin{array}{l}\text { Recursos da Fundação Vitae possibilitam difundir a Experimentoteca para outras } 20 \\
\text { cidades. Depósito da patente de propriedade intelectual da Experimentoteca. }\end{array}$ \\
\hline 1992 & $\begin{array}{l}\text { Trabalhos de pós-graduação: dissertações de mestrado de Diniz (A experimentação } \\
\text { e o ensino de ciências no } 1^{\circ} \text { grau: analisando a Experimentoteca de } 7^{a} \text { série) e Joaquim } \\
\text { (Estudando a experimentação no ensino de ciências), ambas pela UFSCar. }\end{array}$ \\
\hline 1994 & $\begin{array}{l}\text { Resolução USP n. 4.077/1994 dissolve o IFQSC, criando o Instituto de Física de São Carlos } \\
\text { e o Instituto de Química de São Carlos. Resolução USP n. 4.078/1994 transforma a CDCC } \\
\text { em um Núcleo de Apoio às Atividades de Cultura e Extensão Universitária. }\end{array}$ \\
\hline 1995 & Resolução USP n. 4.194/1995 intitula o CDCC como Centro, e não mais Coordenadoria. \\
\hline 1998 & $\begin{array}{l}\text { Lançamento da versão comercial da Experimentoteca pela empresa Brinkmobil, com } \\
\text { transferência de royalties à USP. Elaboração d'O livro da Experimentoteca. }\end{array}$ \\
\hline 2000 & Publicação d'O livro da Experimentoteca. \\
\hline 2001 & $\begin{array}{l}\text { Resolução CoCEX n. 4.866/2001 vincula o CDCC à Pró-Reitoria de Cultura e Extensão } \\
\text { Universitária. }\end{array}$ \\
\hline 2003 & $\begin{array}{l}\text { Retomada da fase de teste e desenvolvimento de kits, ampliando a abrangência da } \\
\text { Experimentoteca para as disciplinas do ensino médio e a educação matemática. }\end{array}$ \\
\hline 2005 & $\begin{array}{l}\text { Aprovação dos novos protótipos por professores da educação básica e disponibilização } \\
\text { dos novos kits de Física, Química, Biologia e Matemática. }\end{array}$ \\
\hline 2006 & $\begin{array}{l}\text { Trabalho de pós-graduação: dissertação de mestrado de Canales (O Centro de Divulgação } \\
\text { Científica e Cultural da Universidade de São Paulo: um projeto de extensão universitária), } \\
\text { pela UFSCar. }\end{array}$ \\
\hline
\end{tabular}

Figura 1. Cronologia da Experimentoteca (continua)

Fontes: Canales (2006); Ferreira, Castro, Santos e Schiel (2004); Ferreira e Schiel (2001); Schiel (1998, 2001); Schiel, Curvelo e Ferreira (2004). 


\begin{tabular}{|c|l|}
\hline Ano & Acontecimento \\
\hline 2010 & $\begin{array}{l}\text { Ocupação da casa ao lado da sede do CDCC (R. Nove de Julho, 1883) pelo setor responsável } \\
\text { pela Experimentoteca. }\end{array}$ \\
\hline 2013 & $\begin{array}{l}\text { Expirado o contrato de patente com a Brinkmobil, celebra-se um novo com a empresa } \\
\text { Central do Saber. }\end{array}$ \\
\hline 2014 & $\begin{array}{l}\text { Trabalho de pós-graduação: tese de doutorado de Mori (Experimentação no ensino } \\
\text { de Química: contribuições do Projeto Experimentoteca para a prática e para a formação } \\
\text { docente), pela USP. }\end{array}$ \\
\hline
\end{tabular}

Figura 1. Cronologia da Experimentoteca (continuação)

Fontes: Canales (2006); Ferreira, Castro, Santos e Schiel (2004); Ferreira e Schiel (2001); Schiel (1998, 2001); Schiel, Curvelo e Ferreira (2004).
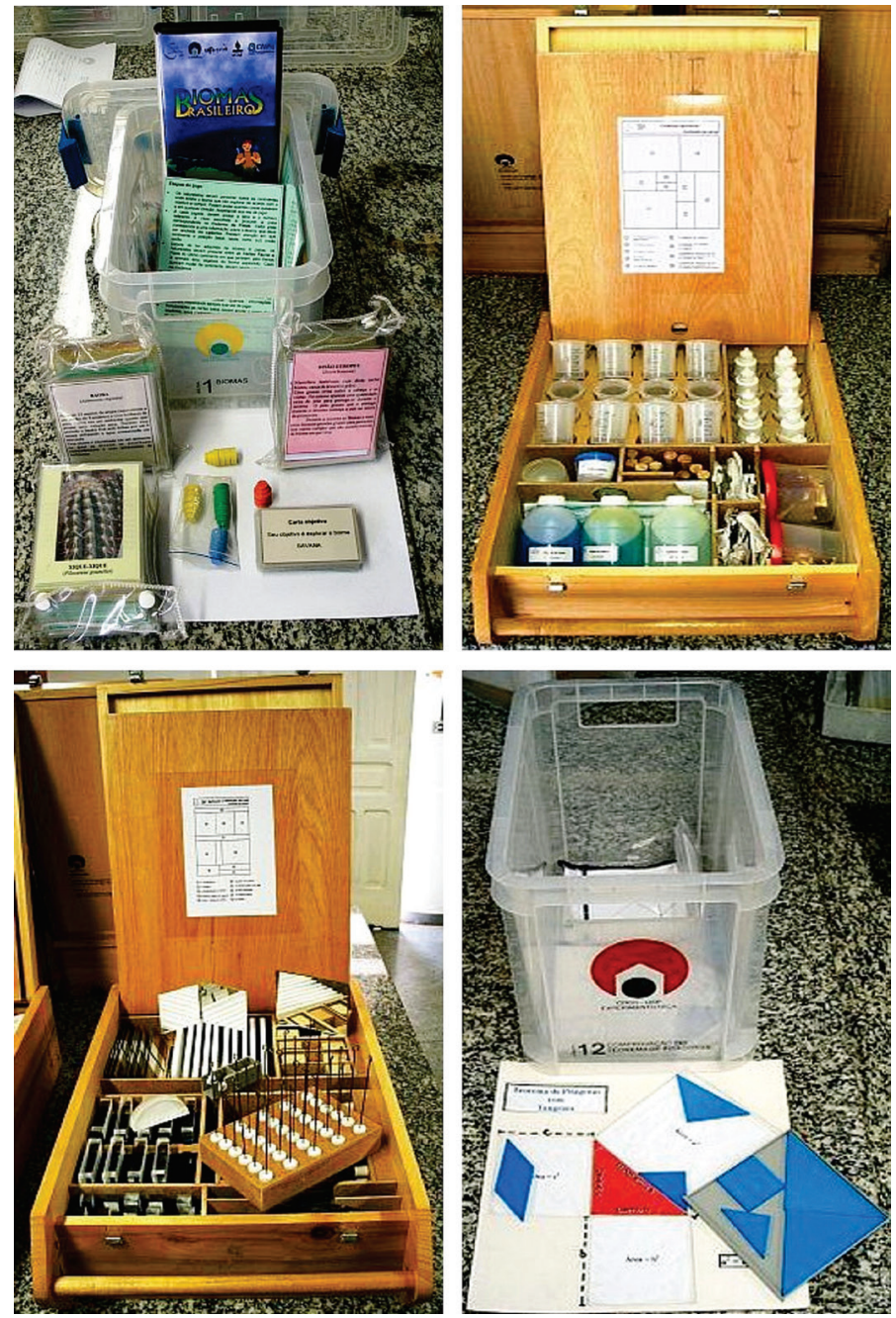

Figura 2. Mosaico de kits da Experimentoteca. Da esquerda para a direita, e de cima para baixo: Biomas, Cinética química, Reflexão e refração da luz e Comprovação do Teorema de Pitágoras

Fonte: acervo de José Braz Mania 


\section{Compromissos teóricos n'O livro da Experimentoteca}

O livro da Experimentoteca: educação para as Ciências da Natureza através de práticas experimentais (Tomazello, \& Schiel, 2000) possui dois volumes. O primeiro apresenta 207 páginas e o segundo, não paginado, contém somente os roteiros experimentais dos kits para o ensino fundamental. Portanto, nosso objeto será apenas o volume 1 do livro, cuja capa é reproduzida na Figura 3. A obra se divide da seguinte maneira:

Apresentação

Prefácio

1) A experimentação em sala de aula e a construção do conhecimento pelo aluno

2) A dimensão ambiental no ensino de ciências

3) Como a matéria se apresenta no ambiente

4) Fenômenos cíclicos na natureza relacionados com o ciclo energético

5) Os habitantes da terra

6) A ação do homem no ambiente

7) O mundo visto por meio da Física

8) O mundo visto por meio da Química

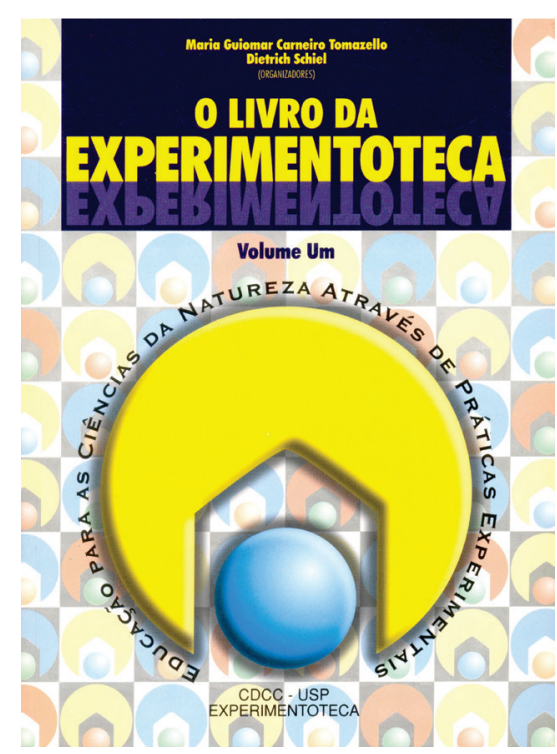

Figura 3. Capa do volume 1 d'O livro da Experimentoteca

Fonte: Tomazello e Schiel (2000) 
A Apresentação da obra, escrita por Dietrich Schiel, resume a história da Experimentoteca e justifica a publicação do livro pela ausência de "um texto que reunisse informações metodológicas para a aplicação em classe” (Tomazello, \& Schiel, 2000, p. 7). Neste trabalho analisaremos apenas as divisões do livro cujos conteúdos mencionem ou interessem ao ensino por investigação, Prefácio e A experimentação em sala de aula e a construção do conhecimento pelo aluno. Elas foram redigidas por Célia Margutti do Amaral Gurgel e possuem, cada uma, a extensão de 4 páginas. ${ }^{1}$

O Prefácio introduz o referencial que, presume-se, orientará os capítulos vindouros d'O livro da Experimentoteca. Tratar-se-ia de um modo integrado de abordar as relações entre fatos científicos, criação/uso de tecnologias e ressonâncias sociais desses dois elementos:

Essa tendência procura enfatizar temas importantes para os interesses e preocupações dos estudantes, relações significativas e claras entre o assunto e as formas de conhecimento aplicadas e/ou utilizadas pela comunidade em geral, e a investigação do problema a partir de projetos, com questões propostas pelos estudantes e avaliação das informações precedentes de várias fontes. Por outro lado, muitos países estão introduzindo em seus currículos escolares uma educação científica apoiada em uma disciplina transversal denominada Ciência-Tecnologia-Sociedade (C-T-S), cuja ênfase seria de extrema relevância social (Tomazello, \& Schiel, 2000, p. 9).

Ao explicar o caráter dessa "disciplina transversal", a autora ressalta sua relação com a formação da cidadania, palavra que aparece em destaque no texto. De fato, esse é um aspecto central do Movimento CTS, que possui diversas vertentes, sendo que a versão propagada n'O livro da Experimentoteca se inspira em Hofstein, Aikenhead e Riquarts (1988). Ainda, o texto estabelece o seguinte silogismo: a abordagem CTS favorece uma tomada de decisões de forma mais consciente e embasada, o que contribui para uma participação cidadã na sociedade democrática e, ao mesmo tempo, esclarece a população acerca da natureza do empreendimento científico. Nas palavras do Prefácio,

A sociedade é uma instituição humana, na qual ocorrem mudanças científicas e tecnológicas. E o ensino por meio da Ciência, sob a perspectiva CTS, pretende preparar os cidadãos a partir do conhecimento mais amplo da Ciência e de suas implicações com a vida. Seu objetivo é desenvolver no indivíduo a capacidade de tomar decisões frente aos problemas sociais, tecnológicos, econômicos e políticos, o que significa prepará-lo para participar ativamente da sociedade contemporânea (Tomazello, \& Schiel, 2000, p. 10).

O texto considera a dimensão ambiental integrada com ciência, tecnologia e sociedade - elementos identificados, respectivamente, com ambiente natural, ambiente artificial e ambiente social. Isso traria consequências para a atividade experimental didática:

A proposição de uma prática pedagógica das atividades experimentais sob a

1 Note-se que, apesar de tomarmos como objeto de análise dois textos da autoria de Gurgel, as próximas citações e transcrições das palavras da autora permanecerão indicadas pela referência a Tomazello e Schiel, os organizadores da coletânea em que se encontram os textos. 
perspectiva ambiental tem justamente essa finalidade: permitir a professores e alunos um redimensionamento de suas concepções sobre o ensino e aprendizagem das Ciências, proporcionando, dessa forma, condições efetivas para a superação do modelo de ensino fragmentado e a-histórico, hoje predominante em nossas escolas, além de contribuir para a formação de indivíduos capazes de questionar e interferir nos caminhos da sociedade em que vivem (Tomazello, \& Schiel, 2000, p.10).

Tais considerações antecipam o conteúdo da divisão seguinte, $A$ experimentação em sala de aula e a construção do conhecimento pelo aluno (que nos interessa mais, por suas menções explícitas à experimentação investigativa). De fato, há proximidades entre a abordagem CTS e o ensino experimental por investigação, ao menos no imaginário dos pesquisadores. É o que sugere a pesquisa de Santos e Schnetzler (2003), que sondou opiniões de estudiosos brasileiros da área de educação em química sobre o ensino CTS:

Quanto à inclusão da experimentação na proposta de ensino de química para a cidadania, os educadores justificaram sua importância em função de seu papel investigativo e pedagógico de auxiliar o aluno na compreensão dos fenômenos químicos, propósito este que não demanda condições sofisticadas na escola.

Ficou evidenciado, também, que o papel da experimentação não seria no sentido da formação de cientistas, como foi concebido pelos projetos inovadores de ensino de ciências da década de sessenta (p. 107).

O início do capítulo traça um histórico da experimentação no ensino de ciências, com críticas à era dos projetos e à aprendizagem por redescoberta - identificada com "uma visão pedagógica empirista, indutiva e positivista da Ciência e do cientista" (Tomazello, \& Schiel, 2000, p. 16). Pelo contrário, para a autora, é necessário que os trabalhos práticos se transformem em situações-problema que estimulem a investigação:

Isso significa criar novas possibilidades de forma a permitir aos alunos criar novas hipóteses, relacionar e comparar dados, alcançando, com o auxílio do professor - mediador desse processo - resultados que possam cotejar com os obtidos pela comunidade científica. Restringir-se a contar a história de como as investigações foram realizadas não torna os alunos sujeitos da operação realizada e, conseqüentemente, não avança na metodologia científica. [...]

Assim, o ensino de Ciências desprovido de preocupação problematizadora e/ou crítica e de articulação entre teoria e prática, baseado apenas em roteiros assépticos, acaba por reduzir a associação do trabalho científico com a prática experimental, fragilizando as pesquisas nas escolas e contribuindo para um vazio de significado em suas transmissões. Tal procedimento torna o saber ilusório, fragmentado e desatualizado em sua base teórica e alheio à realidade dos alunos (Tomazello, \& Schiel, 2000, p. 16).

Esse discurso reaparece em outros momentos do texto, como no exemplo abaixo:

A metodologia de trabalho sugerida a seguir para as atividades práticas em sala de aula tem como pressuposto que a solução de problemas deve ser contemplada como tarefa básica no ensino de Ciências. [...] Por serem de natureza aberta, os procedimentos 
científicos utilizados neste processo também possibilitam aos alunos, a partir de situações-problema, desenvolver formas de resolução mais ricas e complexas em relação aos exercícios fechados. Tal tarefa fomenta a criatividade, característica fundamental do trabalho científico (Tomazello, \& Schiel, 2000, p. 17).

A experimentação com situações-problema tornou-se característica de propostas educacionais construtivistas e, no Brasil, aparece bem representada pela produção do grupo liderado por Anna Maria Pessoa de Carvalho (que, inclusive, tem uma obra citada no capítulo em análise). Orientando-se por tais pressupostos, o texto d'O livro da Experimentoteca propõe as seguintes "fases fundamentais do processo investigativo":

Fase preliminar: planejamento de uma situação-problema com enunciado aberto, para que os alunos resolvam em equipe. O professor os orienta a levantar material bibliográfico sobre o assunto e a registrar/documentar as leituras mais importantes. As fontes podem ser livros, revistas, jornais, etc.

Fase de enfoque: com um plano de ação, apresentado pelo professor, evidencia os objetivos da pesquisa e explicita as hipóteses ou questões norteadoras do trabalho. É necessário que os alunos coloquem suas idéias acerca das variáveis e da natureza das influências sobre o processo.

Fase de aplicação e análise: os alunos já devem estar preparados para buscar soluções ao problema proposto. O professor estimula os grupos, apresentando diferentes questões problematizadoras para reflexão e debate, levantando novas hipóteses, estabelecendo inter-relações e comparando-as com outras situações. O confronto ou a criação de conflitos cognitivos entre as hipóteses levantadas e os resultados obtidos pelos alunos exigem do professor análise teórica e revisão crítica do trabalho. Caso os resultados não se mostrem satisfatórios, serão retomados passo a passo, para que o processo não se perca em tratamentos puramente operativos e difíceis de analisar (Tomazello, \& Schiel, 2000, p. 17).

Conceituando a análise de conteúdo como um conjunto de técnicas de estudo de comunicações, de acordo com a definição de Bardin (2016) - que considera, ainda, que tais técnicas não se restringem a descrever corpora de textos, mas possibilitam a tomada de inferências -, vejamos como se comportam as duas divisões d'O livro da Experimentoteca quando examinadas conforme esse referencial metodológico. Afinal, como já foi exposto, O livro da Experimentoteca é o principal cânone pedagógico e epistemológico do projeto do CDCC, e se há inferências a serem tomadas sobre as relações entre a Experimentoteca e o ensino por investigação, estas devem proceder de uma análise desse material. De fato, a reunião dos excertos acima já seria suficiente para sustentar a inferência de que a abordagem investigativa é altamente valorizada pelo material do CDCC. No entanto, gostaríamos de confirmar essa impressão a partir de um método mais objetivo e menos dependente das escolhas subjetivas do analista.

Assim, empregamos aqui a técnica conhecida como análise de coocorrências, com foco na categoria sintática substantivo. Como desejamos investigar o posicionamento 
pedagógico de um dado emissor, que diz respeito à forma como esse emissor articula e subordina diferentes conceitos do universo educacional (como professor, aluno, ensino, etc.), tomou-se como foco tal categoria sintática - afinal, conceitos são substantivos (nomes). De acordo com Bardin (2016), esse tipo de análise se assenta no princípio de que a coocorrência (ou não coocorrência) de dois ou mais elementos revela sua associação (ou dissociação) no espírito do locutor. Essas estruturas associativas ou dissociativas se estabelecem como núcleos de contingências e sua análise, nas palavras da autora, "parece ter utilidade para clarificar as estruturas da personalidade, as 'preocupações latentes' individuais ou coletivas, os estereótipos, as representações sociais e as ideologias" (p. 263) veiculados no discurso de um dado emissor.

No caso de nosso corpus, foram consideradas coocorrências as presenças simultâneas de substantivos em um mesmo segmento de texto, delimitado como uma unidade de até 40 palavras. Como a análise foi temática, e não lexicométrica, o tratamento prévio do corpus buscou eliminar palavras sinônimas, incorporando-as a uma mesma categoria. Por exemplo, aparições de "estudante" foram substituídas por "aluno", termo mais frequente.

A técnica foi aplicada com o auxílio do software IRAMUTEQ ${ }^{\mathrm{mix}}$ (Interface de $R$ pour les Analyses Multidimensionnelles de Textes et de Questionnaires). A Figura 4 exibe como resultado uma árvore de similitude dos conjuntos de termos que coocorreram no corpus. Essa árvore de similitude procurou evidenciar a relevância de um dado tema no discurso analisado (destacando em tamanhos maiores os conceitos mais mencionados, como "aluno", "ensino", "professor", "processo", "problema", "ciência"), explicitando também as coocorrências mais comuns (por meio da espessura das linhas de ligação entre os substantivos - compare-se as relações mais coocorrentes entre "professor" e "aluno" do que, por exemplo, entre "professor" e "livro").

A análise de conteúdo evidenciou a centralidade do conceito "aluno" nos textos, sugerindo a influência de pedagogias não-diretivas, como o construtivismo. Ainda, observando-se a Figura 4, nota-se que o "ensino" é a instância mediadora entre "aluno" e "ciência" - conhecida ou vivida por meio de uma "ação" ou um "processo". Percebese também que o "professor" não participa da linha de coocorrências que liga "aluno" a "ciência". Isso reforça a inferência de que os textos, ao propor compromissos teóricos para a Experimentoteca, se aliam a uma visão menos dirigida do processo de ensino e da atividade experimental, com foco sobre o estudante, e não sobre o docente. 


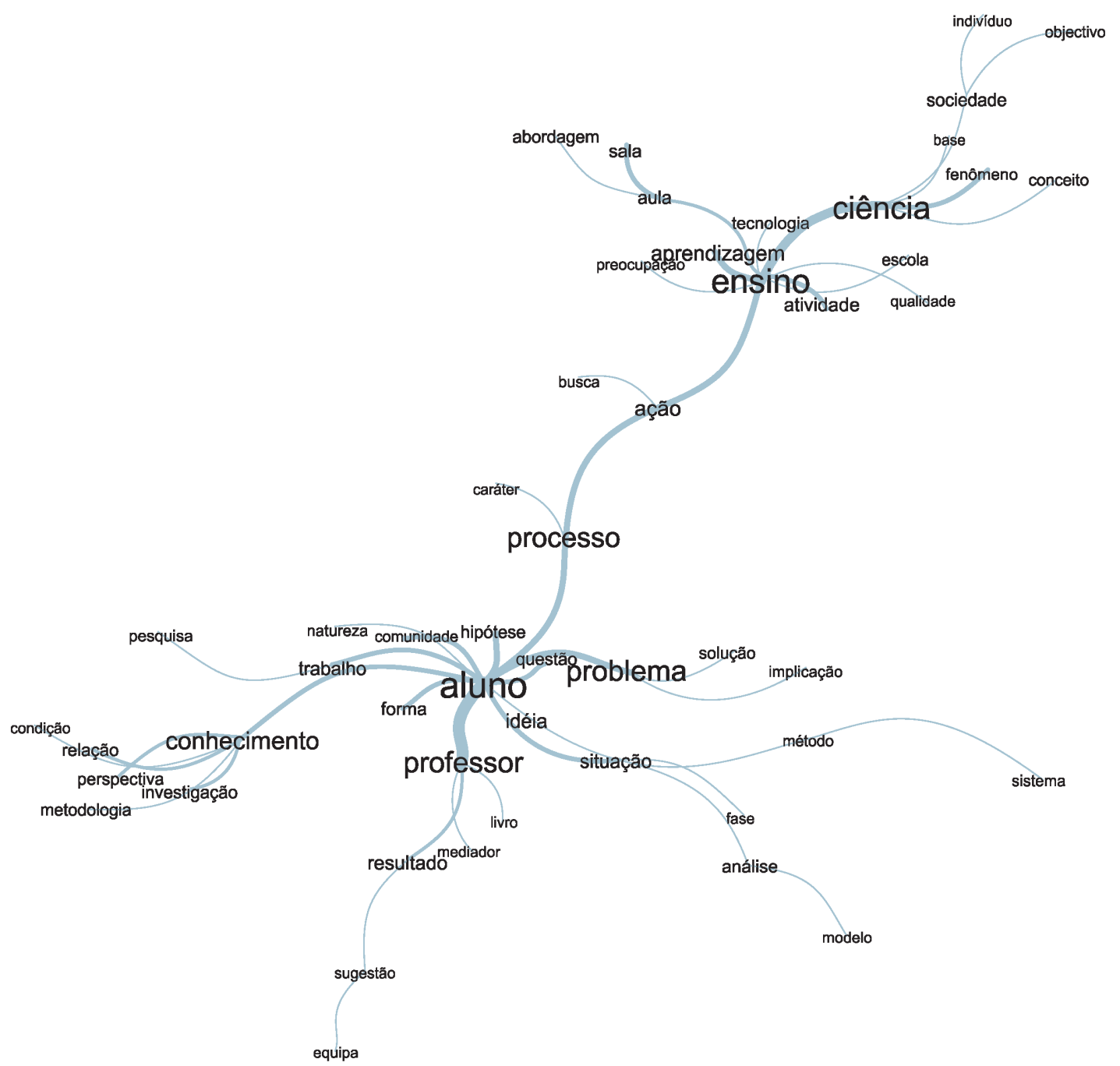

Figura 4. Árvore de similitude resultante da análise d'O livro da Experimentoteca, com foco nas divisões que mencionam o ensino por investigação, tomando as coocorrências de substantivos

\section{Esforços (e limites) práticos em resultados de pesquisas}

Retomemos a última transcrição da fonte, na seção anterior. Considerando as fases propostas para a experimentação, evidencia-se n'O livro da Experimentoteca consonâncias com as atividades investigativas, dado que as fases de enfoque e de aplicação e análise abrangem levantamento de hipóteses pelos estudantes - por sua vez, orientadoras das demais etapas, como montagem do aparato experimental, observações e coletas de dados e tomada de conclusões. Pode-se afirmar que O livro da Experimentoteca defende, portanto, atividades da categoria V, conforme a Figura 5.

Ainda observando a Figura 5, entendemos que, grosso modo, o rótulo de experimentos com caráter investigativo pode ser aplicado às atividades das categorias VI, V e IV. A categoria III referir-se-ia ao chamado laboratório estruturado; a categoria 
II, ao laboratório de verificações, em que os resultados do trabalho experimental já foram antecipados pelo professor; e a categoria I, às demonstrações experimentais (que, em alguns casos, podem se apresentar de forma mais aberta).

\begin{tabular}{|l|c|c|c|c|c|c|}
\hline \multirow{2}{*}{ Etapa do procedimento } & \multicolumn{7}{|c|}{ Categoria da atividade } \\
\cline { 2 - 7 } & I & II & III & IV & V & VI \\
\hline Elaboração do problema & P & P & P & P & P & A \\
\hline Hipótese & P & P & P & P & A & A \\
\hline Plano de trabalho & P & P & P & A & A & A \\
\hline Montagem dos instrumentos & P & A & A & A & A & A \\
\hline Observações/coleta de dados & P/A & A & A & A & A & A \\
\hline Conclusões & P/A & P & A & A & A & A \\
\hline
\end{tabular}

Figura 5. Instrumento para classificar atividades experimentais de acordo com o grau de participação requerido do professor $(\mathrm{P})$ ou do aluno $(\mathrm{A})$.

Fonte: adaptado de de Jong (1998)

Nesta seção, discutimos se 1) a forma de apresentação da Experimentoteca incentiva a realização de atividades menos estruturadas, ou mais afeitas ao ensino por investigação; e 2) as práticas envolvidas em seu uso promovem o trabalho experimental de tipo investigativo na educação escolar. Essas duas questões se relacionam ao modo como os kits experimentais efetivamente adentram o ambiente escolar, e como ali são mobilizados diante dos conteúdos escolares. Portanto, são questões que podem explicitar os esforços práticos envolvidos na articulação da Experimentoteca com o ensino por investigação.

A primeira questão pode ser respondida por meio, novamente, das técnicas de análise de conteúdo (Bardin, 2016). Empregando a análise categorial e considerando a Figura 5 como a grelha de categorias capaz de classificar o material de estudo, tomamos como corpus o conjunto dos roteiros experimentais que compõem os kits da Experimentoteca. Essa técnica de análise de conteúdo foi escolhida por estarmos interessados na tomada de inferências e na explicitação de conteúdos comuns a determinado conjunto de comunicações - no caso, os roteiros experimentais. De modo a compreender os possíveis efeitos da publicação d'O livro da Experimentoteca sobre o projeto, selecionamos apenas os roteiros referentes ao ensino médio, posteriores à obra. Ainda, restringimos a análise aos kits de Química (9), considerando-os representativos diante do corpus total de kits de ciências para o ensino médio (32).

Poderíamos apresentar os resultados graficamente, mas não há necessidade: a maior parte dos experimentos se insere na categoria III, laboratório estruturado. Os kits de número 1 (Compostos iônicos e compostos moleculares), 6 (Eletroquímica) e 8 (Química orgânica) apresentam também procedimentos típicos da categoria II (laboratório de verificações), quando antecipam os acontecimentos em observação - por exemplo, orientando os executores da atividade a encerrar os experimentos ao serem observadas 
"mudanças". Ou seja, nenhum dos experimentos foi classificado entre as categorias IV, V e VI, mais afeitas ao ensino por investigação, uma vez que todos kits veiculam roteiros em que se requer dos alunos, no máximo, montagens, observações/coletas de dados e conclusões. (Se no lugar da análise categorial, realizássemos uma análise lexical e sintática, verificaríamos a predominância de verbos no infinitivo impessoal, com sentido imperativo - colocar, montar, adicionar, agitar, deixar, anotar, repetir, espalhar, aquecer, mergulhar, dissolver etc. -, sugerindo o caráter prescritivo dos roteiros experimentais e, portanto, sua preferência por atividades mais estruturadas, das categorias II e III).

A segunda questão, referente às práticas de uso da Experimentoteca, pode ser respondida por meio de uma pesquisa de tipo bibliográfico e documental (Gil, 2008) elegendo como corpus, desta vez, os estudos em nível de pós-graduação sobre a Experimentoteca. Dois deles foram realizados antes (Diniz, 1992; Joaquim, 1992) e dois após (Canales, 2006; Mori, 2014) a publicação d'O livro da Experimentoteca. Essa pesquisa bibliográfica (e cujo caráter documental se deve ao fato de as teses e dissertações reunirem documentos textuais, principalmente em seus anexos, que servem como testemunhos de uma época ou de um determinado contexto) se justifica por esses trabalhos registrarem mais de duas décadas de informações sobre a Experimentoteca de forma fragmentada no espaço e no tempo, sem que um olhar sistemático pudesse apreender a unidade na diversidade, de modo a articular suas considerações a um tema comum. Assim, pensamos que o tema "ensino por investigação" possa alinhar os resultados dessas pesquisas - muitos dos quais permaneceram restritos às próprias páginas dos trabalhos de pós-graduação, não tendo vindo a público por meio de outros suportes.

O trabalho de Diniz (1992) é um estudo de caso envolvendo uma classe do atual $8^{\circ}$ ano do ensino fundamental, em uma escola pública de São Carlos. Registros em áudio das aulas observadas foram complementados por entrevistas com alunos e com o docente. As falas discentes se mostraram unânimes em favor da experimentação como estratégia de ensino. A entrevista com o professor apontou um grau de satisfação elevado quanto ao material do CDCC: "você não poderia mudar a Experimentoteca, você tem que mudar a estrutura da escola, porque a Experimentoteca não tem o que mudar" (Diniz, 1992, p. 146). O docente destacou também vantagens associadas aos kits: é possível adaptar seu uso para diversas finalidades, como demonstrações ou trabalho experimental de maior ou menor estruturação; há material suficiente para todos os alunos; os aparatos experimentais vêm praticamente prontos para o trabalho, necessitando de poucas montagens; e se trata de um material específico para as ciências, dispensando improvisações. Então Diniz traça conclusões gerais, com algumas críticas às aulas acompanhadas em sua pesquisa:

Não houve de fato uma situação prévia em que o tema, a ser abordado durante a aula prática de laboratório, tenha sido discutido entre os alunos de modo que anteriormente passasse a se configurar para os mesmos como um problema a ser solucionado, no sentido de se buscar um entendimento mais completo do fenômeno, a partir da experimentação, e não apenas a comprovação ou prova de que este realmente ocorre 
(Diniz, 1992, p. 155-156).

Para Diniz, há um uso pouco crítico dos materiais por parte dos docentes; o projeto deveria possibilitar atividades menos direcionadas; os kits deveriam incentivar um trabalho mais contínuo e integrado, em que a experimentação fosse apenas uma etapa, no lugar de servir à comprovação das teorias; e professores e alunos não deveriam quedar tão dependentes dos roteiros dos kits. Em resumo, a Experimentoteca seria "sem dúvida, um facilitador em termos operacionais, mas não necessariamente em termos de aprendizagem dos alunos" (Diniz, 1992, p. 185).

Já o trabalho de Joaquim (1992) foi realizado a partir de entrevistas com 21 docentes de Ciências para o atual $6^{\circ}$ ano ( 15 deles, usuários da Experimentoteca), das 22 escolas públicas de São Carlos que ofertavam o $1^{\circ}$ grau (ensino fundamental) à época. Segundo os dados, a maior parte dos professores aprovava o projeto Experimentoteca, dizendo que ele "É importante" e "Acredito nele". Os dados mostram ainda que os usuários da Experimentoteca utilizavam experimentos frequentemente, conduzindo-os de forma mais planejada e menos improvisada, inversamente ao que parecia ocorrer nas práticas dos não usuários. Ainda, os usuários utilizavam os kits de forma a ilustrar o conteúdo, depois das aulas teóricas, "coerentemente com a característica tendendo a laboratório estruturado apresentada pelos kits", que se "prestam mais à natureza ilustrativa/demonstrativa que à natureza investigativa/redescoberta da experimentação" (Joaquim, 1992, p. 110). A propósito, os sujeitos de pesquisa manifestaram opiniões divididas quanto ao papel do roteiro dos kits: quatro professores usuários acreditavam que o uso exclusivo dos roteiros inibia a criatividade dos estudantes, mas $36,8 \%$ dos sujeitos, entre usuários e não usuários, discordavam veementemente. De fato, mais adiante, aparece uma defesa dos roteiros experimentais pela autora da dissertação:

A preocupação em cercear o aluno mostrou-se desnecessária pois o roteiro que a princípio é fator de segurança e acomodação, parece incapaz de conter as inúmeras interações e representações mentais que ocorrem no aluno quando interage com o material, com as novas situações, avançando em suas interpretações (Joaquim, 1992, p. 157).

Assim, os dois trabalhos de pós-graduação publicados antes d'O livro da Experimentoteca, a partir de diferentes perspectivas teórico-metodológicas (para Diniz, construtivismo e estudos de caso; para Joaquim, pedagogias progressistas e pesquisa quantitativa), verificaram um uso da Experimentoteca praticamente restrito à experimentação mais estruturada, não observando práticas de ensino por investigação. Ainda, seus autores atribuíram distintos juízos de valor a esses resultados.

Em que pese o fato de os trabalhos seguintes, de Canales (2006) e Mori (2014), não terem investigado propriamente uso da Experimentoteca, os depoimentos colhidos por esses pesquisadores permitem algumas inferências sobre as práticas dos professores que utilizam a Experimentoteca em suas atividades profissionais.

Canales (2006) tomou diversas fontes de dados: relatórios anuais de empréstimos dos kits da Experimentoteca, preparados pelo próprio CDCC; depoimentos da educadora Vanilde de Fátima Bongiorno, responsável pelo setor da Experimentoteca; 
falas de estudantes usuários dos kits, de duas escolas públicas de São Carlos; e a fala de uma docente de Biologia de uma das escolas estaduais do município. Foram propostas aos estudantes cinco questões: 1) O trabalho prático com material da Experimentoteca fez com que você entendesse melhor a teoria aprendida em sala de aula?; 2) O seu interesse pelas disciplinas química, física e biologia aumentou depois do uso do material da Experimentoteca?; 3) Você acha fácil fazer os experimentos da Experimentoteca?; 4) Pretende fazer curso superior ligado às ciências exatas?; e 5) Se na questão anterior, a resposta foi afirmativa, responda se o interesse em curso superior na área de exatas foi despertado a partir do contato com o material da Experimentoteca. Nas duas escolas, apesar de a maioria dos estudantes responder afirmativamente às questões 1 a 3 (ainda que as respostas da questão 2 apareçam divididas em uma das turmas), apenas 2 estudantes, em um universo de 72, o fazem quanto à questão 4. Segundo Canales (2006),

Um dos alunos entrevistados ao ser questionado se o material da Experimentoteca tinha lhe despertado interesse pelas ciências, revelou: "A aula foi legal. A gente fez uma mistura e depois, com o fogo que a gente colocou, cada coisa se separou da outra".(p. 108)

Nesse depoimento, ficou evidente a inaptidão do aluno em relacionar o papel da experiência com os conteúdos escolares. Também vale a pena conferir a fala da professora entrevistada:

[...] o aluno não está acostumado à observação de experimentos desde os primeiros anos do ensino fundamental e, portanto, tem dificuldade em enxergar a teoria aplicada se o professor não auxiliá-lo. Mesmo assim, ela [a professora] confirma que o material da Experimentoteca é valioso para que os estudantes visualizem a teoria (Canales, 2006, p. 108).

Assim, no que tange ao ensino por investigação, o depoimento da professora indicou que não há como os alunos do ensino médio utilizarem autonomamente os kits, pois não estão familiarizados com o ensino experimental, sendo irreal esperar atividades das categorias IV em diante na educação escolar. Ainda, se compararmos a fala da depoente com o diagrama da Figura 4, produzido pela análise d'O livro da Experimentoteca, nota-se que a prática relatada não parece viabilizar a pretensão teórica de que o "ensino" medeie a relação (ou a aproximação) entre "aluno" e "ciência".

Por fim, há o trabalho de Mori (2014) - de todos, o que menos observou a Experimentoteca em uso, não coletando declarações de professores ou alunos usuários do projeto. Apesar disso, apresenta a transcrição de uma entrevista com um dos pesquisadores envolvidos com a Experimentoteca desde seus princípios, ainda nos anos 1980. Reproduzimos as seguintes passagens desse depoimento:

[...] embora não se falasse na época da Experimentoteca de abordagem investigativa, os testes que a gente fazia nas escolas, eles mostravam que tava faltando alguma coisa. [...] hoje o professor vai até o CDCC, retira a caixa [da Experimentoteca] mas eu não sei o que ele tá fazendo com ela. Né... Bom. Isso começou a ficar claro pra gente nessa ocasião do desenvolvimento da Experimentoteca. Então, o que começou a me incomodar é o seguinte: a gente tem que ter alguma coisa que sirva de piloto pra nós, mas que seja mais 
permanente. Que seja desvinculado com o desenvolvimento da Experimentoteca (Mori, 2014, p. 412).

A partir desse ponto, o entrevistado descreve esses projetos "piloto", fomentados por diferentes instituições, que aliavam materiais da Experimentoteca à formação contínua de professores. Essas oportunidades de aperfeiçoamento docente visavam, entre outros objetivos, incorporar metodologias como o ensino por investigação à prática do ensino de ciências nas escolas municipais e estaduais. No entanto, como fica claro em momentos seguintes da entrevista (conferir a p. 413 em diante, na fonte pesquisada), tais iniciativas exigiam uma relação colaborativa entre universidade e escola, o que nem sempre se concretizava, principalmente em virtude de características da estrutura organizacional da educação básica, como a alta rotatividade dos corpos gestor e docente nas escolas. Infere-se, portanto, que a experimentação com viés investigativo, mesmo sob o auxílio dos kits da Experimentoteca, depende de outras condições materiais e institucionais para, efetivamente, se incorporar à prática dos professores.

Em resumo, assim como os dois trabalhos publicados antes d'O livro da Experimentoteca, as duas pesquisas de pós-graduação posteriores à obra apresentam evidências de que o ensino por investigação, embora perseguido pelos esforços de diversos sujeitos envolvidos na formulação e no uso da Experimentoteca, ainda não é uma realidade na prática de seus usuários, esbarrando em limites de diversas naturezas.

\section{Considerações finais: uma agenda para a Experimentoteca}

Quem está dando 40 aulas por semana não consegue... você querer que ele dê as 40 aulas de uma forma extremamente dinâmica e agitada, mobilizando todos os alunos... ele não vai passar de 02 meses e vai "empacotar". Então, infelizmente, os professores limitam o uso [da Experimentoteca] por causa de uma questão de resistência física dele. Isso só se resolveria baixando a carga horária do professor. Um absurdo! Na Universidade dou 06 horas de aula por semana. Essa carga da rede não há como justificá-la!

Quero dizer que a Experimentoteca não existe sozinha, ela está inserida numa realidade social e a gente sabe que está dando uma pequena contribuição, mas outras coisas têm também que contribuir simultaneamente (Joaquim, 1992, p. 176).

O depoimento acima, prestado por Dietrich Schiel ainda em 1992, menciona questões que permanecem pendentes, passadas quase três décadas.

Embora historicamente os formuladores da Experimentoteca tenham esperado que o projeto viabilizasse práticas dissociadas da tradição do ensino experimental superando o empirismo-indutivismo dos laboratórios de verificação, assim como os experimentos excessivamente roteirizados e dirigidos -, tais intenções nem sempre encontraram condições favoráveis para se concretizar.

Recuperemos as questões de pesquisa apresentadas no início do texto:

a) Quais são os compromissos teóricos da Experimentoteca com o ensino por investigação? 
b) Como esses compromissos são acompanhados de esforços práticos, por parte de idealizadores e de usuários da Experimentoteca, visando a realização de atividades experimentais mais coerentes com a abordagem investigativa?

Com relação aos compromissos teóricos da Experimentoteca com a abordagem investigativa, nossos resultados mostraram a existência de uma concepção sobre a experimentação focada nos processos de elaboração de hipóteses e, principalmente, nas atividades desenvolvidas autonomamente pelos alunos, cujas ações (e não o professor) medeiam sua relação com o saber sistematizado. Essa concepção materializou-se na edição d'O livro da Experimentoteca, na tentativa de responder acusações de críticos, como as de que o projeto apenas estaria reeditando empreendimentos (em muitos casos, malogrados) de décadas atrás, como os kits da parceria IBECC-Funbec e as reformas curriculares estadunidenses e inglesas.

Quanto aos esforços práticos, outros resultados apontaram contradições, tanto internas quanto externas aos processos em análise. As contradições internas se explicitaram na análise dos roteiros dos kits experimentais que, mesmo produzidos após a edição d'O livro da Experimentoteca, não demonstram obedecer aos compromissos teóricos expostos nessa obra. Já as contradições externas - cujos indícios foram fornecidos por outras pesquisas sobre a Experimentoteca - são resultado dos atritos e das resistências que o projeto, gestado no âmbito da educação não escolar sistematizada (o museu ou centro de ciências), encontra ao ingressar no contexto da educação escolar. Esses obstáculos têm como componentes a estrutura organizacional da educação, as condições de trabalho dos docentes, os processos de formação inicial e continuada desses mestres, entre outros.

Retomemos o que afirmamos na introdução deste trabalho: a presente pesquisa é orientada por um enfoque crítico-dialético. Nesse sentido, parece coerente que nossos resultados tenham destacado contradições nos processos analisados, principalmente quanto à relação entre teoria e prática, problematizando (ou questionando) sua materialização em práxis (Gamboa, 2004; Sanfelice, 2008). No entanto, nosso empreendimento não estaria completo, de acordo com tal enfoque metodológico, caso se detivesse nas contradições, recusando-se a contribuir para sua superação. Frigotto (2004), falando das pesquisas dialéticas, nos lembra que sua preocupação fundamental deve ser "refletir, pensar, analisar a realidade com o objetivo de transformá-la" (p. 82).

Sendo assim, que propostas os dados desta investigação nos autorizam a formular, de forma a constituir uma agenda para a Experimentoteca e para a pesquisa futura que a tome como objeto?

Quanto ao nível de propósito, consideramos necessários novos subsídios aos kits já existentes da Experimentoteca para aliá-la a outras possibilidades de trabalho experimental, mais coerentes com a fundamentação proposta n'O livro da Experimentoteca. Nesse sentido, seria interessante o desenvolvimento de novos roteiros, a serem adicionados aos roteiros anteriores, facultando aos professores a escolha por atividades mais ou menos estruturadas, conforme as exigências de sua prática. 
Assim, cada caixa da Experimentoteca viria acompanhada de cinco ou seis roteiros diferentes, indicando aos docentes formas para se trabalhar com os kits conforme as diversas modalidades ou categorias de atividades experimentais. Mesmo a formação contínua docente se beneficiaria desse material que expusesse, claramente, as diferentes modalidades de trabalho experimental no ensino.

Também no nível de propósito, seria imprescindível uma reedição d’O livro da Experimentoteca, levando em consideração as sugestões do parágrafo acima, e buscando atualizar elementos do texto de 2000 que possam soar datados, hoje em dia. Por outro lado, intuições do livro original que se mostraram acertadas - por exemplo, o investimento na teoria dos perfis conceituais (que não pudemos analisar neste trabalho), incipiente ao final do século XX, mas com um avanço considerável na atualidade, vide o conteúdo da obra de Mortimer e El-Hani (2014) - mereciam ser aprofundadas em uma nova publicação.

Quanto ao nível da prática, ressaltamos a necessidade de permanente mobilização, por parte dos professores da educação básica - e da sociedade civil como um todo - por melhores condições de exercício da docência. Tais reivindicações, que vão ao encontro da fala de Schiel que abre estas considerações finais, são condições indispensáveis para a valorização da prática educativa e para que o potencial de projetos como a Experimentoteca, que resiste há mais de 30 anos, não se perca em meio às vicissitudes da carente estrutura educacional brasileira.

\section{Agradecimentos}

Agradecemos à Coordenação de Aperfeiçoamento de Nível Superior (CAPES), pelo financiamento.

\section{Referências}

Araújo, M. S. T., \& Abib, M. L. V. S. (2003). Atividades experimentais no ensino de física: diferentes enfoques, diferentes finalidades. Revista Brasileira de Ensino de Física, 25(2), 176-194. Recuperado de http://www.scielo.br/scielo.php?script=sci_ arttext\&pid=S1806-11172003000200007\&lng=en\&tlng=pt

Bardin, L. (2016). Análise de conteúdo. 3. reimpr. Lisboa: Edições 70.

Canales, R. P. (2006). O Centro de Divulgação Científica e Cultural da Universidade de São Paulo: um projeto de extensão universitária. (Dissertação de Mestrado em Educação). Centro de Educação e Ciências Humanas da Universidade Federal de São Carlos, São Carlos.

Cazelli, S., Marandino, M., \& Studart, D. (2003). Educação e comunicação em museus de ciências: aspectos históricos, pesquisa e prática. In G. Gouvêa, M. Marandino, \& M. C. Leal (Orgs.), Educação e museu: a construção social do caráter educativo dos museus de ciências (pp. 83-106). Rio de Janeiro: Access/Faperj. 
De Jong, O. (1998). Los experimentos que plantean problemas en las aulas de química: dilemas y soluciones. Enseñanza de las Ciencias, 16(2), 305-314. Recuperado de http:// www.raco.cat/index.php/Ensenanza/article/view/21536/21370

Diniz, R. E. S. (1992). A experimentação e o ensino de ciências no $1^{\circ}$ grau: analisando a Experimentoteca de $7^{\mathrm{a}}$ série. (Dissertação de Mestrado em Educação). Centro de Educação e Ciências Humanas da Universidade Federal de São Carlos, São Carlos.

Ferreira, E. R. O., Castro, A. C., Santos, S. A. M., \& Schiel, D. (2004). Características, estrutura e desenvolvimento do trabalho do Centro de Divulgação Científica e Cultural. Divulgações do Museu de Ciências e Tecnologia, 4, 55-60.

Ferreira, E. R. O., \& Schiel, D. (2001). Centro de Divulgação Científica e Cultural. In S. Crestana, E. W. Hamburger, D. M. Silva, \& S. Mascarenhas (Orgs.), Educação para a ciência: curso de treinamento em centros e museus de ciência (pp. 611-615). São Paulo: Livraria da Física.

Frigotto, G. (2004). O enfoque da dialética materialista histórica na pesquisa educacional. In I. Fazenda (Org.). Metodologia de pesquisa educacional (pp. 69-90). 9. ed. São Paulo: Cortez.

Gamboa, S. A. S. (2004). A dialética na pesquisa em educação: elementos de contexto. In I. Fazenda (Org.). Metodologia de pesquisa educacional (pp. 91-115). 9. ed. São Paulo: Cortez.

Gaspar, A. (2006). A teoria de Vigotski: um novo e fértil referencial para o ensino das ciências. (Tese de Livre Docência). Faculdade de Engenharia da Universidade Estadual Paulista Julio de Mesquita Filho, Guaratinguetá.

Gaspar, A. (2014). Atividades experimentais no ensino de Física: uma nova visão baseada na teoria de Vigotski. São Paulo: Livraria da Física, 2014.

Gil, A. C. (2008). Métodos e técnicas de pesquisa social. 6. ed. São Paulo: Atlas.

Hofstein, A., Aikenhead, G., \& Riquarts, K. (1988). Discussions over STS at the fourth IOSTE symposium. International Journal of Science Education, 10(4), 357-366. doi: $10.1080 / 0950069880100403$

Joaquim, C. L. M. (1992). Estudando a experimentação no ensino de ciências. (Dissertação de Mestrado em Educação). Centro de Educação e Ciências Humanas da Universidade Federal de São Carlos, São Carlos.

Kasseboehmer, A. C., Hartwig, D. R., \& Ferreira, L. H. (2015). Contém química 2: pensar, fazer e aprender pelo método investigativo. 2. ed. São Carlos: Pedro \& João.

Krasilchik, M. (1987). O professor e o currículo das ciências. São Paulo: EPU, 1987.

Marandino, M. (2017). Faz sentido ainda propor a separação entre os termos educação formal, não formal e informal? Ciência \& Educação, 23(4), 811-816. doi: 10.1590/1516731320170030001 
Marandino, M. (Org.). (2008). Educação em museus: a mediação em foco. São Paulo: Geenf/FEUSP.

McManus, P. (1992). Topics in museums and science education. Studies in Science Education, 20(1), 157-182. doi: 10.1080/03057269208560007

Megid Neto, J. (1999). Tendências da pesquisa acadêmica sobre o ensino de ciências no nível fundamental. 1999. (Tese de Doutorado em Educação). Faculdade de Educação da Universidade Estadual de Campinas, Campinas.

Meneghetti, R. C. G. (2011). Experimentoteca de matemática: discussões sobre possibilidades de sua utilização no processo de ensino e aprendizagem de Matemática. Práxis Educativa, 6(1), 121-132. doi: 10.5212/PraxEduc.v.6i1.0011

Mori, R. C. (2014). Experimentação no ensino de Química: contribuições do Projeto Experimentoteca para a prática e para a formação docente. (Tese de Doutorado em Química). Instituto de Química de São Carlos da Universidade de São Paulo, São Carlos.

Mori, R. C., \& Curvelo, A. A. S. (2016). O pensamento de Dermeval Saviani e a educação em museus de ciências. Educação e Pesquisa, 42(2), 491-506. doi: 10.1590/S15179702201604144612

Mortimer, E. F., \& El-Hani, C. N. (Eds). (2014). Conceptual profiles: a theory of teaching and learning scientific concepts. New York: Springer.

Sanfelice, J. L. (2008). Dialética e pesquisa em educação. In: J. C. Lombardi, \& D. Saviani. (Orgs.), Marxismo e educação: debates contemporâneos (pp. 69-94). 2. ed. Campinas: Autores Associados/HISTEDBR.

Santos, W. L. P., \& Schnetzler, R. P. (1997). Educação em química: compromisso com a cidadania. Ijuí: Unijuí.

Schiel, D. (2001). A construção do conhecimento pelo aluno no programa Experimentoteca. In S. Crestana, E. W. Hamburger, D. M. Silva, \& S. Mascarenhas (Orgs.), Educação para a ciência: curso de treinamento em centros e museus de ciência (pp. 261-264). São Paulo: Livraria da Física.

Schiel, D. (1998). Centro de Divulgação Científica e Cultural de São Carlos: o centro de ciência em toda parte. In: S. Crestana, M. G. Castro, \& G. R. M. Pereira (Orgs.), Centros e museus de ciência: visões e experiências: subsídios para um programa nacional de popularização da ciência (pp. 189-195). São Paulo: Saraiva.

Schiel, D., Curvelo, A. A. S., \& Ferreira, L. H. (2004). Projeto Experimentoteca: a contribuição do design. Divulgações do Museu de Ciências e Tecnologia, 4, 149-154.

Tomazello, M. G. C., \& Schiel, D. (Orgs). (2000). O livro da Experimentoteca: educação para as ciências da natureza através de práticas experimentais. Piracicaba: VITAE/ Unimep/USP. 
Rafael Cava Mori

${ }^{\circledR}$ http://orcid.org/0000-0001-6301-2795 Universidade Federal do ABC

Centro de Ciências Naturais e Humanas

Santo André, Brasil rafael.mori@ufabc.edu.br

Antonio Aprigio da Silva Curvelo

${ }^{\circ}$ http://orcid.org/0000-0003-0377-7707

Universidade de São Paulo Instituto de Química de São Carlos

Departamento de Físico-Química São Carlos, Brasil aprigio@iqsc.usp.br

Submetido em 31 de Janeiro de 2018 Aceito em 18 de Maio de 2018 Publicado em 27 de Julho de 2018 